Portland State University

PDXScholar

Environmental Science and Management

Professional Master's Project Reports

2009

\title{
Calculating the Volume of the May 18, 1980 Eruption of Mount St. Helens
}

Dâvid Nuñez Wickham

Portland State University

Follow this and additional works at: https://pdxscholar.library.pdx.edu/mem_gradprojects

Part of the Environmental Sciences Commons, and the Volcanology Commons Let us know how access to this document benefits you.

\section{Recommended Citation}

Wickham, Dâvid Nuñez, "Calculating the Volume of the May 18, 1980 Eruption of Mount St. Helens" (2009). Environmental Science and Management Professional Master's Project Reports. 9.

https://pdxscholar.library.pdx.edu/mem_gradprojects/9

https://doi.org/10.15760/mem.29

This Project is brought to you for free and open access. It has been accepted for inclusion in Environmental Science and Management Professional Master's Project Reports by an authorized administrator of PDXScholar. Please contact us if we can make this document more accessible: pdxscholar@pdx.edu. 
Calculating the Volume of the May 18, 1980

Eruption of Mount St. Helens

Community Partner-United States Army Corps of Engineers, Hydrological, Coastal, and River Engineering Section Portland Office by Dâvid Nuñez Wickham A project report submitted in partial fulfillment of the requirements for the degree of

Masters of Environmental Management

Portland State University

2009 


\section{Table of Contents}

Abstract $\quad$ i

$\begin{array}{ll}\text { Acknowledgements } & \text { iii }\end{array}$

List of Tables $\quad$ iv

List of Figures $\quad$ v

I. Introduction 1

A. Project Purpose

B. History of Mt. St. Helens Eruptions 1

C. The Main Event: 1980 Eruption 2

D. Consequences of the Eruption 2

E. Calculating the Total Volume of the Sediment and Debris 3

$\begin{array}{ll}\text { II. Methods } & 4\end{array}$

A. Study Area $\quad 4$

$\begin{array}{ll}\text { B. Materials } & 6\end{array}$

$\begin{array}{ll}\text { C. Software and Procedure } & 8\end{array}$

$\begin{array}{ll}\text { Results } & 22\end{array}$

IV. Discussion and Conclusion 24

A. Limits of the Data $\quad 24$

B. Sediment Erosion and Deposition 25

$\begin{array}{ll}\text { C. Interpolation and DEMs } & 27\end{array}$

D. Recommendations for Further Study and Future of Project 28

References $\quad 30$ 


\begin{abstract}
An abstract of the project report of Dâvid Nuñez Wickham for the Masters of Environmental Management presented June 12, 2009.
\end{abstract}

Title: Calculating the Volume of the May 18, 1980 Eruption of Mount St. Helens

The May 18, 1980 eruption of Mount St. Helens created a massive amount of sediment and debris, thought to be as much as 5.5 billion cubic yards. This sediment causes infill of river stretches and collects along levees protecting southwest Washington State. The sediment must be removed to ensure these areas do not flood. The US Army Corps of Engineers (USACOE) is tasked with flood protection for southwest Washington State and the levees protecting the cities of Castle Rock, Lexington, Kelso, and Longview. The Sediment Retention Dam, opened in 1989 is able to filter out larger particulate but fine grain sediment remains in the water column and is transported further down the river. In order to calculate how much sediment remains to be removed Portland State University's Environmental Sciences and Management program and the USACOE formed a partnership and generated Digital Elevation Models (DEM) from topographic maps made by the United States Geological Survey (USGS). This was accomplished by taking 600 dots per inch (dpi) scanned images of the eruption path, geographically rectifying them in ESRI's ArcMap software environment, and running Iterative Self-Organizing Data Analysis Technique (ISODATA) Unsupervised Classification utilizing ERDAS Imagine 9.3 software. After the contour lines were extracted from the images we cleaned up the lines in a raster environment, converted the raster to vector lines, and entered elevations. 
From these contour lines we created the DEM and calculated the volume difference between the pre-eruption 15 minute USGS maps and the 7.5 minute post-eruption quad maps. The volume difference was 7,870,546,345 $\mathrm{m}^{3}$ for Mount St. Helens quads, $4,335,917,517 \mathrm{~m}^{3}$ for Spirit Lake quads, $-220,149,557 \mathrm{~m}^{3}$ for Goat Mtn. in Cougar quads, $-3,155,437,891 \mathrm{~m}^{3}$ for Elk Rock quads, and 734,102,545 $\mathrm{m}^{3}$ for Hoffstadt Mtn. in Elk Rock pre quad. These figures indicated a large generation of sediment and debris on the slope north of Mount St. Helens, sediment deposition in the Hoffstadt Mtn. river reach, and erosion in all other areas. The USACOE will use my raw data contour elevation lines to create their own DEMs incorporating stream locations to further refine the data. From this data they hope to extrapolate how much sediment is left and where the sediment deposits are likely to erode from in the future. 


\section{Acknowledgements}

I would like to thank Matt Fraver and Chris Nygaard of the USACOE for their help in research, obtaining, scanning the maps, obtaining LIDAR data, and with the many day to day problems and issues that arose. I would also like to thank Professor Geoffrey Duh for all his technical help with ArcGIS and ERDAS without which I could not have succeeded so far or fast. Special thanks are due to my Environmental Management adviser Professor Joe Maser whose classes provided both knowledge, interest in this field of study, professional advice, and who always pushed me to do better. Samuel L. Crow for his essential help in manually editing for many long hours in the lab and editing of my paper, Stephen Wilcox for his help in discovering the reverse sieve that fixed many a hole in our lines, and Mavel Morales for all her editing work on this paper. 


\section{List of Tables}

Table 1. Lists the Root Mean Square and Mean Difference of the difference assessment between the 1980 post eruption elevation data and the 2004 USGS LIDAR data.

Table 2. Lists the 15 minute pre eruption maps, the 7.5 minute post eruption maps, and the volume difference calculated. 


\section{List of Figures}

Figure 1. Map of study area city, Sediment Retention Dam, and Mount St. Helen locations. $\quad 3$

Figure 2. Display of topographic map study area for pre eruption Mount St. Helens eruption path.

Figure 3. Display of topographic map study area for post eruption Mount St. Helens eruption path.

Figure 4. Display of original scanned images of the topographic map study areas. 6

Figure 5. Flow chart Model of the Digital Image Contour Extraction or DICE process.

Figure 6. Cropped Image of Mount St. Helens and Vicinity. 10

Figure 7. Image of ISODATA Unsupervised Classification with 160 classes. 12

Figure 8. Image of informational classes assigned to unsupervised classification. 13

Figure 9. Display of recoded raster image.

Figure 10. Image of clump process.

Figure 11 a. Image of contour raster data before sieve process.

Figure $11 \mathrm{~b}$. Image of contour raster data after sieve process.

Figure 12. Tabular display of coefficients of a Low-pass convolution kernel. 16

$\begin{array}{ll}\text { Figure 13. Display of final raster image after all cleaning process complete. } & 18\end{array}$

$\begin{array}{lll}\text { Figure 14. Display of vector lines generated within raster image. } & 18\end{array}$

Figure 15. Display of point images for visualization in ArcScene. 19

Figure 16. Display of Digital Elevation Model or DEM. 20

Figure 17. Goat Mtn. volume change areas and eruption impact demarcation line. 26 


\section{Introduction}

\section{A. Purpose of Project}

This project was initiated to fulfill the requirements of the Masters of Environmental Management degree in the Environmental Sciences and Management program at Portland State University. The objective of the project was to create elevation contour data related to the eruption of Mount St. Helens for the United States Army Corps of Engineers.

\section{B. History of Mount St. Helens Eruptions}

Mount St. Helens has a long history of eruptions that have been document by geologist and by Native peoples of the Pacific Northwest. Mount St. Helens is a stratovolcano. A stratovolcano is a composite volcano made up of alternating layers of ash, volcanic particulate, and lava flow. Unlike its Hawaiian counterparts, that emit relatively slow moving flowing lava, stratovolcanoes are prone to violent eruption. Ancient Mount St. Helens started its growth before the end of the last Ice Age approximately 10,000 years ago. ${ }^{(14)}$ The oldest parts of the mountain erupted about 40,000 years ago onto a landscape of even older volcanic and sedimentary rocks. The stratovolcano continued to erupt after the glaciers receded and nine major activity periods before the eruption of 1980 are currently recognized. The most recent eruption before the 1980 activity began around the year 1800. This eruption was marked by a violent explosion and followed up by numerous small eruptions and emissions of lava. These expulsions of debris and lava led to the creation of the lava dome called Goat Rocks in the year 1857. ${ }^{(14)}$

On March 20, 1980, at 3:47 p.m. Pacific Standard Time (PST), an earthquake measuring 4.2 on the Richter Scale announced a renewed period of volcanic activity after 123 years of relative peace and quiet. Between March 16 and May 16 more than 10,000 earthquakes were 
recorded in and around the vicinity of Mount St. Helens. The afternoon of March 27 saw the first significant ash and steam eruptions in the lower continuous United States since the emissions from Lassen Peak, CA in 1917. ${ }^{(14)}$ Ash rose $6000 \mathrm{ft}$ above Mount St. Helens and formed a $250 \mathrm{ft}$ wide crater inside the formerly snow and ice filled summit cavity. The ash and debris ejected from the stratovolcano originated from phreatic, or steam driven blasts. These blasts were caused by ground water coming into contact with magma, converting into steam and pulverizing the ash, debris, and lava deposits that covered the mountain. ${ }^{(14)}$ The north face of the mountain bulged out to $450 \mathrm{ft}$ its previous size with extrusions of magma that filled the stratovolcano's cavities.

\section{The Main Event: 1980 Mount St. Helens Eruption}

On the morning of May 18, 1980 at about 20 seconds after 8:32 a.m. PDT, the mountain experienced a 5.1 magnitude earthquake approximately 1 mile beneath the volcano. The distended north face of the mountain broke off which lead to the massive landslide, pyroclastic flows, lahars, widespread destruction, and the deaths of 57 people. ${ }^{(14)}$ The eruption spewed approximately 5.5 billion cubic yards of sediment, pyroclastic material, and debris. The debris, sediment, and subsequent lahars moved mainly into Spirit Lake and the North Fork of the Toutle River. $^{(12)}$

\section{Consequences of the Eruption}

Sediment and debris quickly filled the Toutle and Cowlitz rivers while reducing the Columbia river draft bottom from approximately 40 feet to 13 feet. ${ }^{(13)}$ The United States Geological Survey (USGS), the United States Army Corps of Engineers (USACOE), and the Federal Emergency Management Agency (FEMA) all began immediate and long term mitigation procedures. The USACOE began immediate dredging of the Toutle, Cowlitz, and Columbia 
rivers. Continuous dredging kept the rivers from filling with sediment, overflowing their banks, and flooding the nearby cities of Lexington, Castle Rock, Kelso, Longview (See Figure 1). This dredging was done by large earth removal equipment and was costly. In order to drastically reduce these costs and provide a long term sustainable solution the USACOE built a Sediment Retention Dam (SRD). By the time construction of the SRD was well under way in 1987 the dredging had removed 110 million cubic meters of sediment. ${ }^{(14)}$ The SRD is unable to stop fine grain sediment and these sediments continue to collect at levees that directly protect the Washington state cities of Lexington, Castle Rock, Kelso, Longview, and the Interstate 5 corridor.

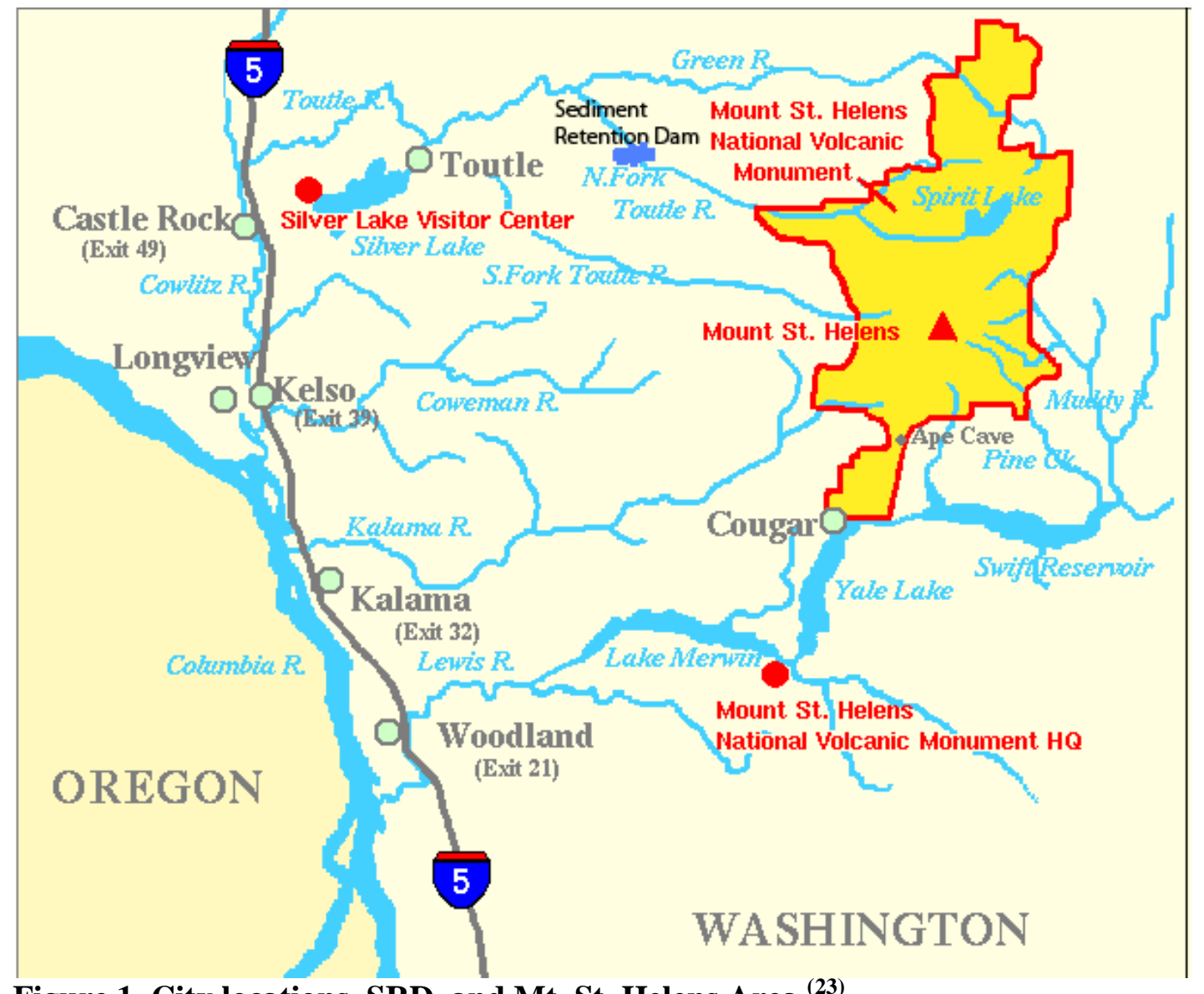

Figure 1. City locations, SRD, and Mt. St. Helens Area ${ }^{(23)}$ 


\section{E. Calculating the total volume of sediment and debris}

The Department of Environmental Sciences and Management at Portland State University and the USACOE formed a partnership in order to address the collection of sediments bypassing the SRD. The goals of this project were to calculate the total volume of sediment and debris produced during the eruption. The data we created was a snapshot of the mountain from before it erupted, 1953-1957 and just after, 1980. This gave us a more accurate picture of sediment deposits than more recently collected data. Matt Fraver, one of our partners at the USACOE, informed us of Light Detection And Ranging (LIDAR) data the USACOE had collected since it was available in 1989 with an accuracy of up to 6 inches. DEM's created from Radio Detection and Ranging (RADAR) satellites like SPOT-1 and RADARSAT-1 were also available by the late 1980s. ${ }^{(17)(18)(19)}$ Due to erosion and continued volcanic activity on Mount St. Helens the LIDAR and RADAR data is not as temporally accurate. The data we created is a more temporally precise historic representation of the mountain and the eruption path. With this more accurate data on the volume and location of sediment deposited the USACOE's sediment specialists will attempt to ascertain where future sediment erosion will take place and how much sediment is left to erode.

\section{Methods}

\section{A. Study Area}

The study area of this project is located in southwest Washington State and consisted of Mount St. Helens, the north and south fork of the Toutle River, and the area west of Spirit Lake. This area began south and east of Mount St. Helens at latitude $46^{\circ} 07^{\prime} 30^{\prime \prime}$ North and longitude $122^{\circ} 07^{\prime} 30^{\prime \prime}$ West. It proceeded as far west and south as the Goat Mountain quadrangle located at latitude $46^{\circ} 07^{\prime} 30^{\prime \prime}$ North and longitude $122^{\circ} 22^{\prime} 30^{\prime \prime}$ West. Its northeast boundary was the 
Spirit Lake West quadrangle at latitude $46^{\circ} 22^{\prime} 30^{\prime \prime}$ North and longitude $122^{\circ} 07^{\prime} 30^{\prime \prime}$ West and its northwest corner was Hoffstadt Mountain quadrangle at latitude $46^{\circ} 22^{\prime} 30^{\prime \prime}$ North and longitude $122^{\circ} 30^{\prime} 00^{\prime \prime}$ West. From these basic topographic outlines each map was studied to find the highest point where mud and debris from the eruption had reached. Just after the eruption USGS and USACOE investigators found that mud had traveled up to $360 \mathrm{ft}$ above the valley floor of the rivers leading away from the mountain. ${ }^{(14)}$ Due to the time constraints of this project, the focus is on areas above $360 \mathrm{ft}$ around the north face of Mount St. Helens, the eruption path west of Spirit Lake, the south fork of the Toutle, and the north fork of the Toutle River. The complete study area for pre and post eruption is shown in Figure 2 and 3.

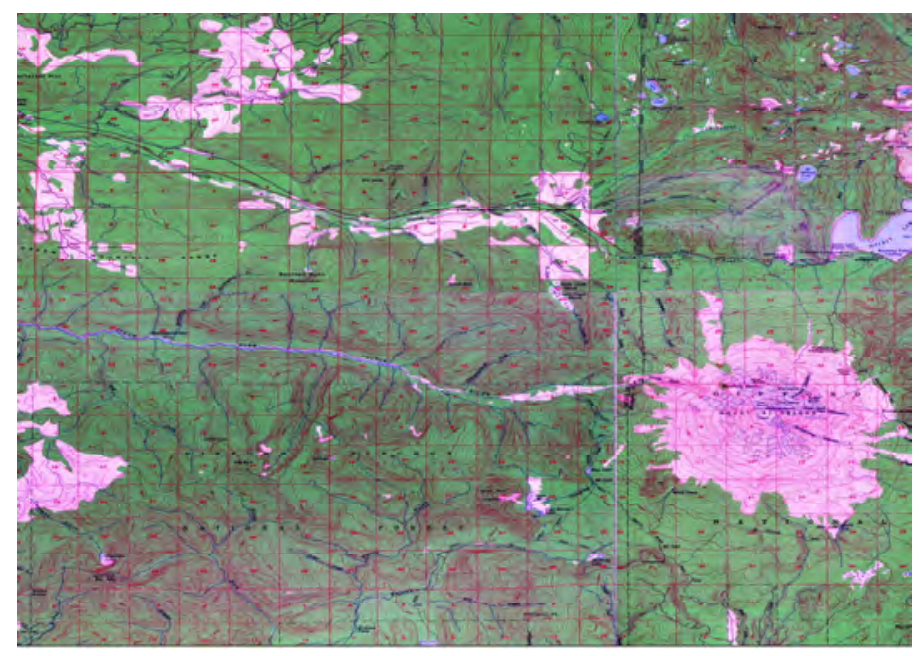

Figure 2. Study Area for Pre-Eruption

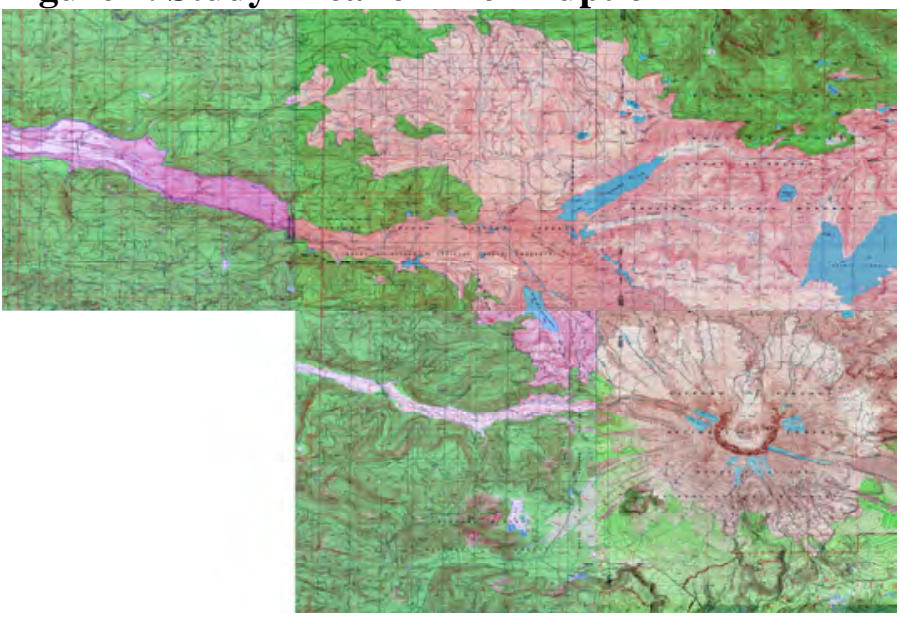

Figure 3. Study Area for Post-Eruption 


\section{B. Materials}

The first step in this process was research and investigation into the specific topographic quadrangles that contained the path of the Mount St. Helens eruption. Generation of contour lines from topographic maps is possible at any accuracy level but the validity of that data, the DEM, is constrained by the number of contour lines present in a map. For this reason we wanted a map with as many contour lines as possible. However, there were only two sets of maps with enough contours made during the required time frames. These sets of maps are the 15 minute and 7.5 minute topographic quadrangles produced by the USGS. The 15 minute quadrangles have contour lines at $80 \mathrm{ft}$ apart and the 7.5 minute maps have contours $40 \mathrm{ft}$ apart.

Mr. Matt Fraver from the USACOE was our partner in research and instrumental in locating the topographic maps. Together we identified 9 essential maps which covered the mountain, the eruption, and the path of the debris. Four of these maps were 15 minute USGS topographic quadrangle maps of the study area made before the eruption. The pre-eruption maps are: Mount St. Helens, Spirit Lake, Cougar, and Elk Rock. Mount St. Helens 15 minute topographic quad was created from aerial photographs in 1952 and field check in 1958. ${ }^{(1)}$ Spirit Lake 15 minute quad was created with aerial photographs taken in 1952 and field checked in 1957. ${ }^{(3)}$ Cougar and Elk Rock 15 minute topographic maps were created in the same way during 1952 and field checked in 1953. (2)(4) The other five maps were 7.5 minute USGS topographic quads and these included Mount St. Helens, Spirit Lake West, Goat Mountain, Elk Rock, and Hoffstadt Mountain. The Mount St. Helens and Elk Rock 7.5 minute topographic maps were created from aerial photographs taken in 1980, field checked in 1981, and printed in 1983 . $^{(5)(6)}$ The Spirit Lake West, Goat Mountain, and Hoffstadt Mountain 7.5 minute topographic maps were created from aerial photographs taken in 1980, field check in 1981, and produced in 1984. 
${ }^{(7)(8)(9)}$ All of these maps were found with the help of the reference librarian at the Portland State University library Map Room. (See Figure 4)

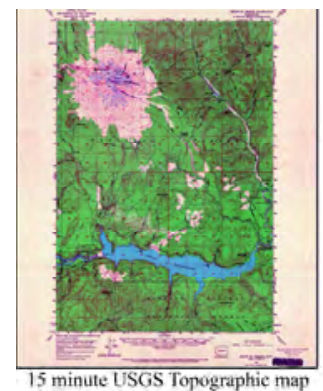

of Mt. St. Helens.

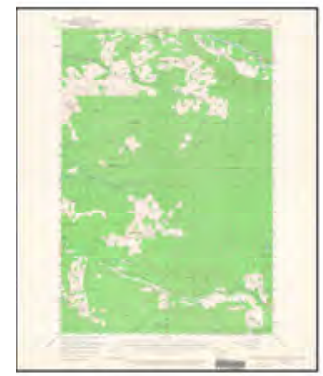

15 minute USGS Topographic map of Elk Rock.

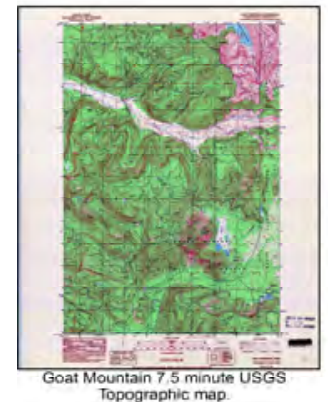

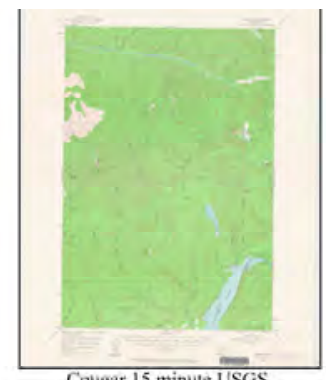

Cougar 15 minute USGS

Topographic map.

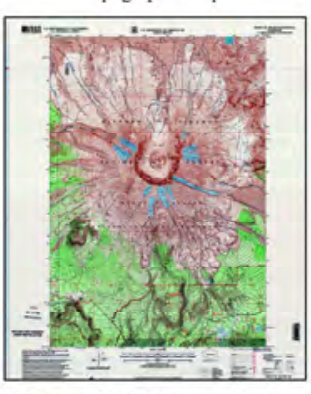

7,5 minute USGS Topographic map of Mt. St. Helens.

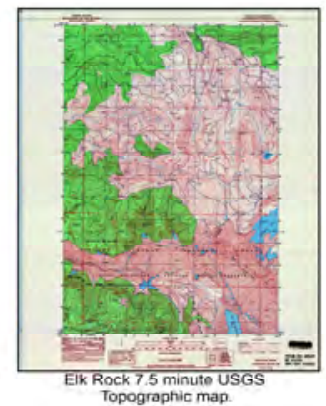

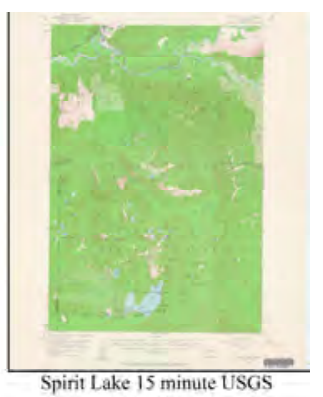

Topographic map.

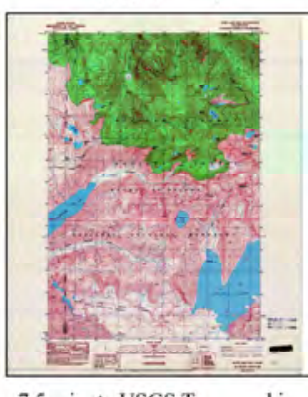

7,5 minute USGS Topographic map of Spirit Lake West.

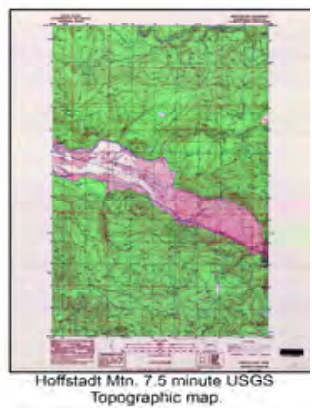

\section{Figure 4. Original Scanned Images of the Study Area}

\section{i. Creating a DEM from historic data}

There are two main methods currently available to create digital terrain data from topographic maps and historic data. Elevation contours, which represent terrain with lines in Geographic Information Software (GIS) can either be created using heads-up digitizing and digital image contour extraction (DICE). When creating elevation contours by hand in a headsup method the map is traced with a mouse or digital cursor. ${ }^{(1)}$ This requires a massive amount 
of time invested as every twist and turn of the line must be traced. This method was not chosen because of the time constraints of our project. Yuyu and Lifan gave an early example of how a map could be scanned, turned into a digital raster image, and the contour lines extracted. ${ }^{(10)}$ Our research into digitizing methods and advice from our PSU technical advisor Professor Geoffrey Duh guided us to choose digital image contour extraction. We chose DICE because it enabled us to quickly and accurately create the contour lines from the original topographic map. A further reason for our use of DICE was our thought that the process, if streamlined and perfected, could greatly reduce human error in contour line generation.

\section{Software and Procedure}

i. Software choices

The main difference between this project and how most previous papers have approached the extraction of contour lines is in the software. There are no out of the box software packages designed to specifically extract contour lines and create spatial data. Most businesses, universities, and previous published papers designed the software and algorithms themselves to extract the contour lines and interpolate the DEM surface. At the suggestion of Professor Geoffrey Duh I decided to use my previous experience with ERDAS Imagine 9.3 and ESRI's ArcMap software environment to accomplish our goals. ERDAS Imagine is geospatial software that is primarily used in remote sensing applications and raster graphic editing. ${ }^{(16)}$ ESRI's ArcGIS Geographical Information Systems (GIS) suite of software is specifically designed to create, edit, and manipulate geospatial data. ${ }^{(15)}$ These two sets of GIS software were essential in our process and available at the PSU Geography computer labs. The alternative to ERDAS and ESRI's software packages would have required us to pay for another suite of software or write the software ourselves. These options were not feasible. 


\section{ii. Digital Image Contour Extraction Process}

\section{Step 1-scanning}

The process for DICE was a long and often difficult procedure. The DICE model (See Figure 5) was created through trial and error. After all the necessary maps were gathered we were able to use the USACOE's Contex Cougar TX 36 + scanner to create 600 dpi images of the topographic maps. 300 dpi images were first used but found to have insufficient detail when attempting to classify them. It was necessary to use the USACOE's scanners as no PSU scanners were capable of processing an 18 " x 22 " 15 minute map or a 22 " x 27 " 7.5 minute map in one whole piece and scanning all the maps at a private business was cost prohibitive.

\begin{tabular}{|c|c|c|c|}
\hline $\begin{array}{l}\text { 1. } \\
\text { Obtain Map }\end{array}$ & $\begin{array}{l}2 . \\
\text { Scan Map and } \\
\text { produce } \\
\text { Image }\end{array}$ & $\begin{array}{l}3 . \\
\text { Rectify Image }\end{array}$ & $\begin{array}{l}4 . \\
\text { Crop Image }\end{array}$ \\
\hline
\end{tabular}

\begin{tabular}{|c|c|c|c|}
\hline $\begin{array}{l}5 . \\
\text { Unsupervised } \\
\text { Classification } \\
\text { \& ISODATA }\end{array}$ & $\begin{array}{l}6 . \\
\text { Informational } \\
\text { Classes } \\
\text { Assigned }\end{array}$ & $\begin{array}{l}7 . \\
\text { Recode of } \\
\text { Image }\end{array}$ & $\begin{array}{l}8 . \\
\text { Clump and } \\
\text { Sieve Image }\end{array}$ \\
\hline
\end{tabular}

\begin{tabular}{|c|c|c|c|}
\hline $\begin{array}{l}9 . \\
\text { Low-pass } \\
\text { Convolution }\end{array}$ & $\begin{array}{l}10 . \\
\text { ArcGIS } \\
\text { manual } \\
\text { editing }\end{array}$ & $\begin{array}{l}11 . \\
\text { Generate } \\
\text { Vector Lines }\end{array}$ & $\begin{array}{l}12 . \\
\text { Addition of } \\
\text { Elevation data }\end{array}$ \\
\hline
\end{tabular}

\begin{tabular}{|c|c|c|}
\hline $\begin{array}{l}13 . \\
\text { Generate } \\
\text { Point Data }\end{array}$ & $\begin{array}{l}14 . \\
\text { Create DEM } \\
\text { with IDW }\end{array}$ & $\begin{array}{l}15 . \\
\text { Volume } \\
\text { Estimation }\end{array}$ \\
\hline
\end{tabular}

\section{Figure 5. The DICE Process}

\section{Step 2-rectification}

These maps were then loaded into ESRI's ArcMap 9.3 software environment and geographically rectified. Rectification is the process of taking an image and giving it spatial coordinates such as latitude and longitude. This was easily accomplished as each map had its latitude and longitude printed at the corners. We recalculated these coordinates from their 
original form of degrees, minutes, seconds into decimal degrees and attached ground control points utilizing the Georeference tool in ArcMap. With these coordinates attached we were able to define the projection of the map into its identified coordinate system, Geographic Coordinate System (GSC) North American 1983 with the North American Datum (NAD) 1927. At this point we transferred the now spatial images into ERDAS Imagine 9.3 software environment.

\section{Step 3-cropping/subsetting}

Once in ERDAS's Imagine 9.3 software environment we cut the map images to just the study area (See Figure 6). This was accomplished through use of the Inquiry Box option and the Data Preparation option of Subset Image. These tools allowed us to crop the image to a desired area. By cropping the rectified image down to just the map contours we reduced the amount of pixels in the image, and eliminated unnecessary areas outside the contour boundaries. These cropped areas consisted of scale bars, names, library identification barcodes, information on the origins of the map, the Universal Transverse Mercator zone, and the longitude-latitude coordinates.

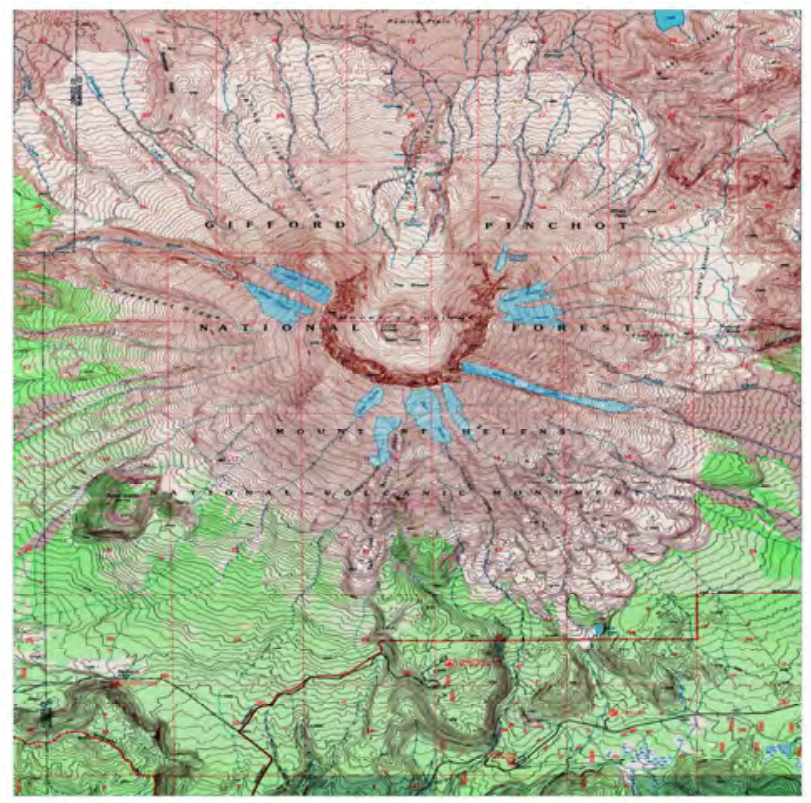

Figure 6. Cropped Image of Mount St. Helens and Vicinity 


\section{Step 4- Unsupervised Classification and ISODATA}

With the images reduced to only the areas of the map containing contour lines we then utilized Unsupervised Classification to identify different pixel colors within the image. When the USGS makes a topographic map many layers are created and then printed on top of each other in a final combination. ${ }^{(11)}$ We attempted to find just the contour line data layer but were unable to locate these components of the final map. After contacting the USGS through email and over the phone we were referred to the USGS archive at Menlo Park, CA. They were unable to locate the contour only data layer maps and stated that the paper copies made decades ago were either lost or destroyed. A classification on the multi-layer combined topographic map was necessary. The Iterative Self-Organizing Data Analysis, or ISODATA, process consists of the computer examining the pixel colors, identifying them, assigning them to classes, and repeating the process until a preset threshold is reached. We used 160 classes to differentiate pixel color. Twenty-five iterations were chosen as the number of times the ISODATA process would run and a standard 95 percent threshold was selected. The threshold tells the software that when less than 5 percent of the pixels change their categories, the classification process stops. We experimented with both the number of classes we created and the percentage of threshold. What we found, as confirmed by the ERDAS software manuals, was that we would need at least 40 classes and that in order to go much higher than 95 percent accuracy required an exponential increase in processing time. Early attempts took as long as 2 hours for each map to classify when the threshold was pushed to 98 percent and no discernable difference was found between the 98 percent threshold and the 95 percent threshold. After attempts at 40 and 80 classes we found that 160 classes were best for allowing the unsupervised classification tool to discern the contour lines from background color grid lines, place names, elevation marks, and many other 
kinds of noise present within the contour line boundaries. Below, in Figure 7, we have the output of unsupervised classification.

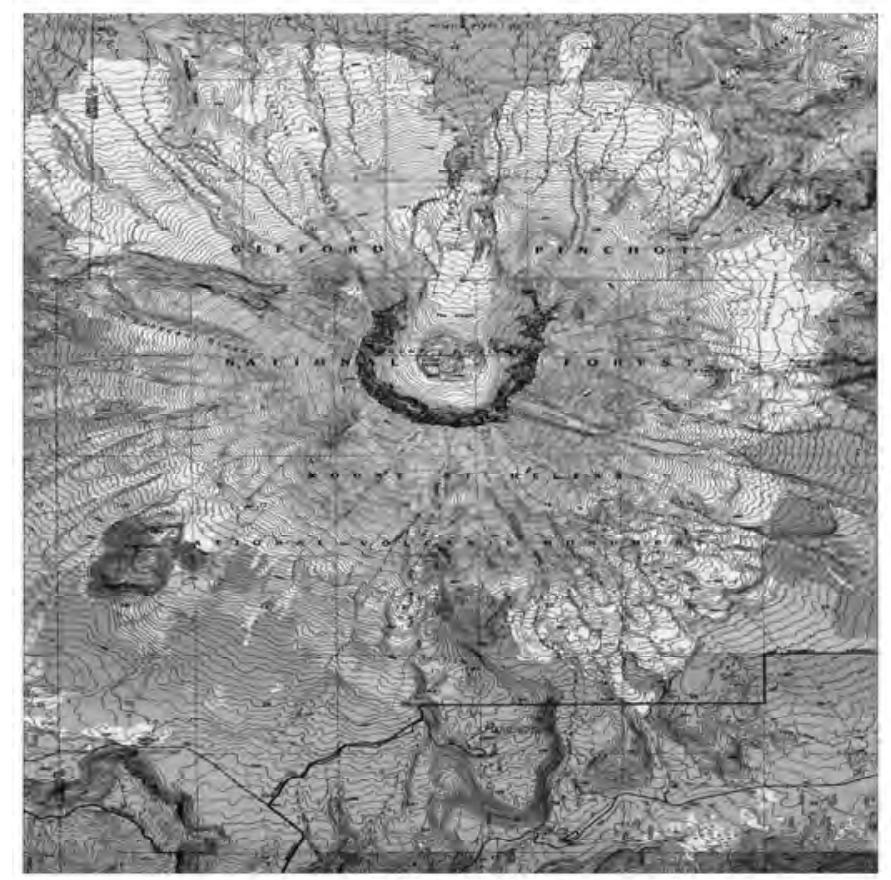

Figure 7. Image of ISODATA Unsupervised Classification with 160 classes.

\section{Step 5-Assigning Informational Classes}

After the ISODATA unsupervised classification had identified 160 separate classes we assigned information categories to each class. This process had many iterations but we finally settled on a color coding system to make the process quicker. ISODATA assigned a gradient of black to white colors for all classes. We reassigned each class a color that would highlight it for visual identification. Red stood for grid lines, names, numbers, elevation numbers, jeep trails, camp sites, footpaths, and other non contour noise. Blue stood for glacier boundary demarcations, rivers, streams, marshes, ponds, and lakes. Yellow stood for the contour elevation lines themselves and grey for any pixel not of those three categories. Figure 8 demonstrates the final result of the information class identification. 


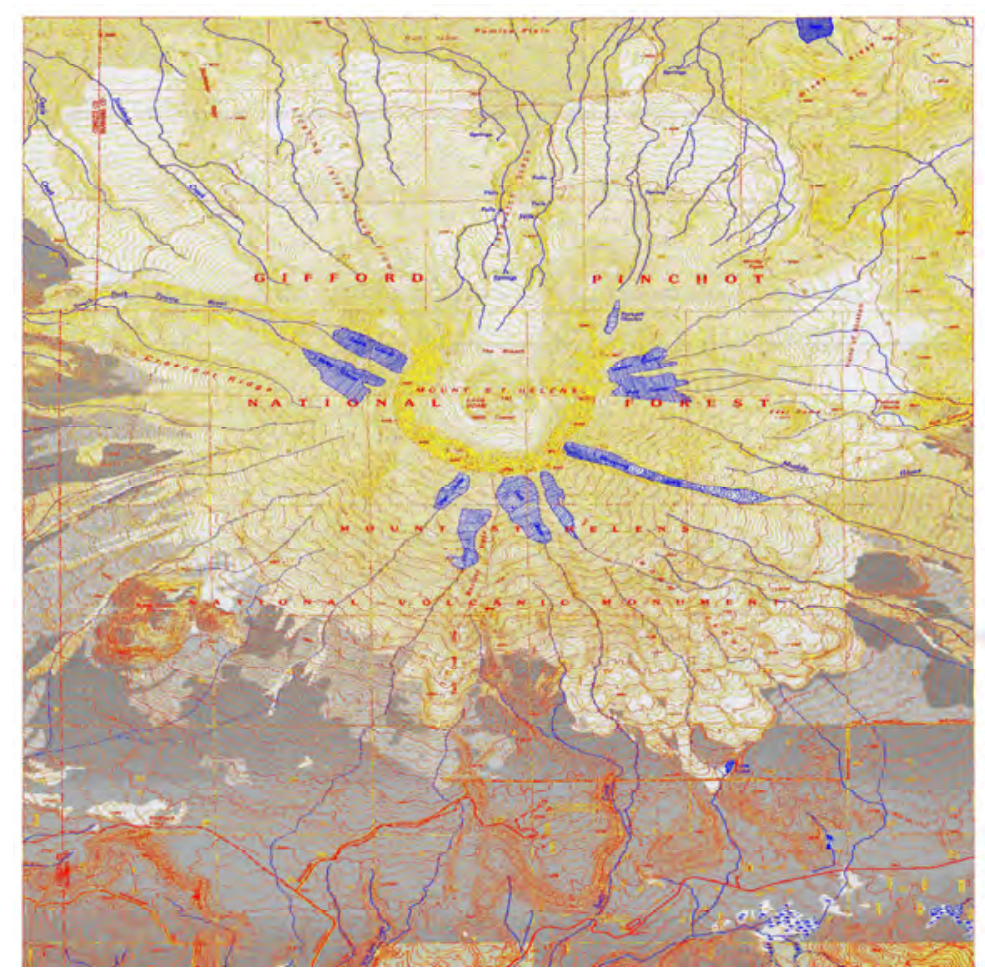

Figure 8. Informational Classes Identified

Step 6-Recoding

Once the informational classes were complete, the recoding process was begun.

Recoding consisted of assigning the pixel to either an off or on state, 1 stood for on, and 0 for off. All pixels had a value ranging from 0 to 160 . The value of the pixel varied as a function of how many classes we previously told ISODATA to create. Recoding consisted of changing all pixels that were contour pixels from their previous value to 1 . All other pixels were assigned a value of 0 (See Figure 9). This was necessary to contrast the image for visual identification of the contour lines but most importantly for the next step in the process. More often than not the pixel classes were so ambiguous that once the "non-contour" pixels were removed there were holes and even breaks in the contour lines. Each hole within the contour line would cause the ArcMap vector generation software to produce a split and an extra contour line that would inaccurately predict the location of the contour elevation line. A break would fragment the 
vector contour lines into small segments that increases the efforts to assign elevation data to contours.

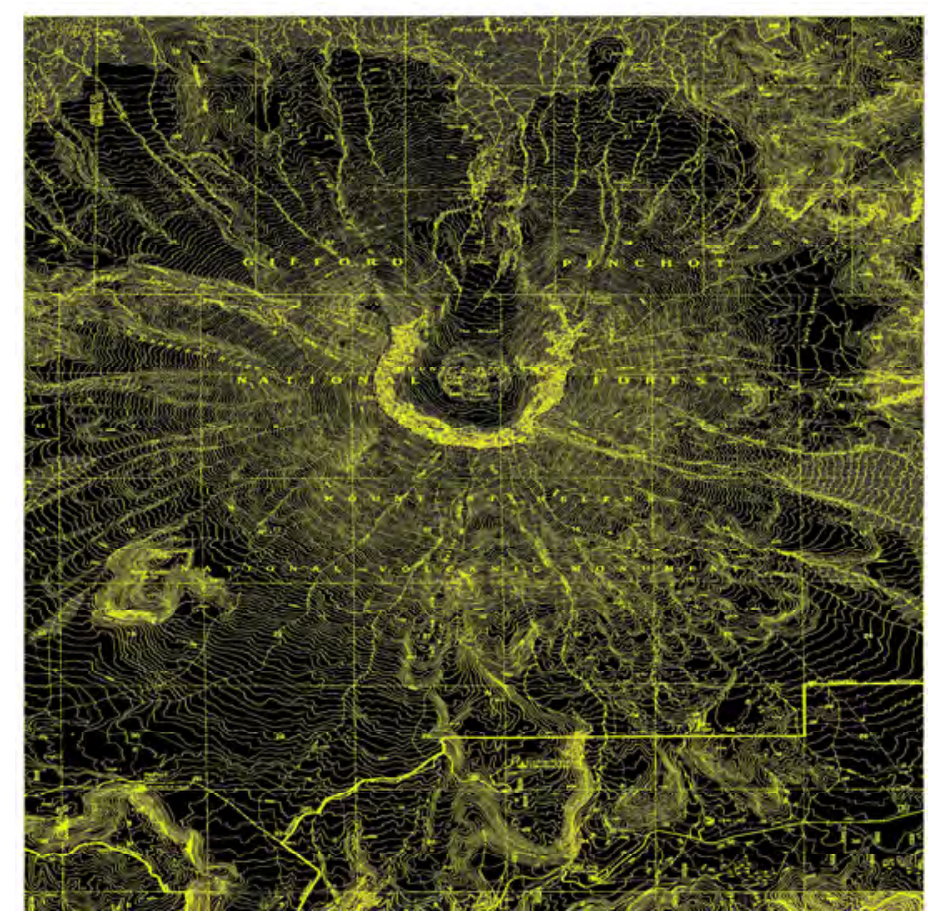

Figure 9. Recoded Raster Image

\section{Step 7-Clump and Sieve}

Once the maps were recoded, depending on how broken and scattered the contour line pixels were, one of two methods was used to clean the maps. In the case of all post-eruption maps, but especially Spirit Lake West, Elk Rock, and Hoffstadt Mtn., mud was portrayed as dots all along the river and up the sides of river valley (See Figure 11a). These mud flow representations were approximately $40-80$ pixels in size and had to be removed. The recoded maps were then run through a process called Clump (See Figure 10). Clump is a process that identifies contiguous groups of pixels which enables the sieve process to remove contiguous clumps of pixels. The sieve tool removed any pixel amount as designated by the user. The pixel number chosen was the most important choice in the sieve process. The bigger the number 
chosen, the larger the pixel group removed. Trial and error showed us that each maps was unique and no set pixel amount was found for all images.

Some maps, like Mount St. Helens post-eruption, could be run at a high sieve rate of 80 pixels. Almost all mud was removed, except where it touched a line, and the sieve process caused no damage to the contour lines (See Figure 11b). This was due in part to the ISODATA classification working well on this map and we made the decision to leave in rivers, letters, and elevations so as not to break the contour lines. Other maps, such as in the case of Elk Rock preeruption, had a massive number of breaks in the contour line. Sieving this map only chewed larger holes in the already sparse contour lines. Another option we discovered was to reverse the Recode previously run, turning off to on, on to off, and running a Clump and Sieve. This process removed some of the holes in our contour lines. In addition to running reverse sieves we could repair broken lines with convolution processes.

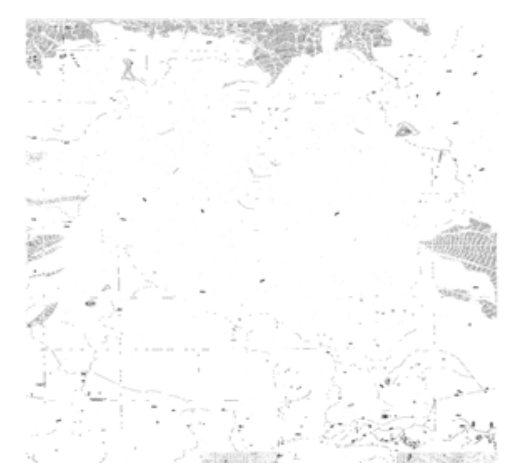

Figure 10. Clump Image

(a)

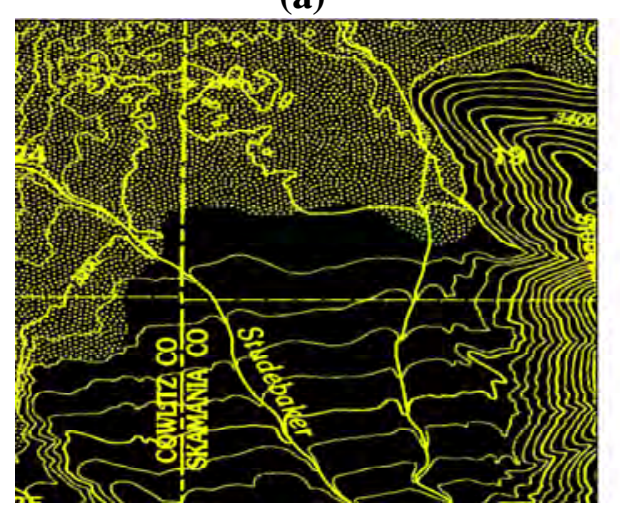

(b)

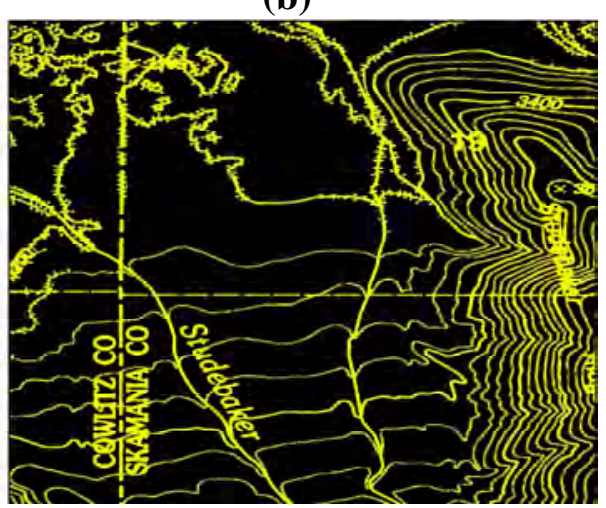

Figure 11. Sieve Image: Before (a) and After (b) 


\section{Step 8-Convolution}

A convolution is a moving kernel, or window, of numbers which can change or average the pixel values as the kernel is applied over the surface of the image. All images are grids of values. In Figure 12 we see one type of convolution window or kernel. This kernel is applied by the computer over all the values of the image in one $3 \times 3$ set at a time. This particular kernel causes a blurring effect. We did not want to change the contour lines, what we wanted was to replace any holes or breaks in the line. The low-pass convolution was particularly useful at repairing holes and breaks in the contour lines.

\begin{tabular}{|r|r|r|}
\hline 1 & 1 & 1 \\
\hline 1 & 0 & 1 \\
\hline 1 & 1 & 1 \\
\hline
\end{tabular}

\section{Figure 12. Coefficients of a Low-pass convolution kernel}

This tool was very useful to fill holes but the expansion of the line often cause a negative effect of letting close contour lines touch. In order to repair lines that had merged we would have to manually edit the contour lines back to their original positions. Once the sieve, low-pass, or in a few cases both procedures were use, the maps were then recoded back to two classes of 0 and 1. A final subset of the raster image was created to just the eruption path. At this point the data was transferred to the ArcMap software environment.

Step 9- Manual Editing of Raster Images in ESRI's ArcMap

\section{i. ArcMap and Necessary Tools}

With the recoded final raster maps opened in ArcMap, their projection defined, manual editing of any errors remaining could begin. The final raster images of the contour lines were added to ArcMap for editing. A number of tools were necessary to edit the raster images of the contour lines. When creating a vector shapefile it was vital to use the spatial database product ArcCatalog which allowed for a line to be generated inside a raster image. 3D Analyst, Spatial 
Analyst, Spatial Adjustment, ArcScan, and Editor were all necessary tools for editing the raster or vector layers. In order to generate a vector line the shapefile made in ArcCatalog had to be created with the same geographic projection as the raster image, GSC NAD 1927. Elevation was added to the attribute table as a floating point field in order to allow for input of elevation numbers with spatial characteristics as opposed to plain text. The original map image was overlaid to make sure the contour lines had generated in position. Raster images of the unsupervised classification were imported to ArcMap with pixel classes highlighted to emphasize major categories like rivers, letters, numbers, major contour lines, and minor contour lines. These steps were taken in order to give the editor a more accurate editing environment.

At this phase we began to manually edit any problems remaining with the raster contour lines. This was a long and laborious process which took days for each map and especially long for the first map attempted, post-eruption Mount St. Helens. Unknown to either us or ESRI's technical support was the problem of editing large files in ArcScan. The very first attempt at saving edits to the file crashed ArcMap and lost an entire day's worth of work. Two thirds of the way into completing the cleanup of post-eruption Mount St. Helens the file became corrupt and it was necessary to start over. At this point we had not cut our study area down to only the eruption path and this lost data representing 2 to 3 weeks worth of editing efforts. After much trial and error we discovered that ERDAS had been creating files at 8 bit data resolution. We resaved our files at 1 bit and greatly reduced the number of crashes we experienced in ArcMap. Many types of errors in the data could only be fixed manually. Major elevation annotations were often either placed over the line, which connected three or four rows, or a section of elevation contours were cut out and the number placed in the hole. Whenever a number, name, or other non contour pixel that came through the editing process was found it was necessary to remove it 
and redraw the contour line. Once all holes, extrusions, breaks in the line, merged, and missing areas had been repaired (See Figure 13) the raster was ready for the next step in the process.

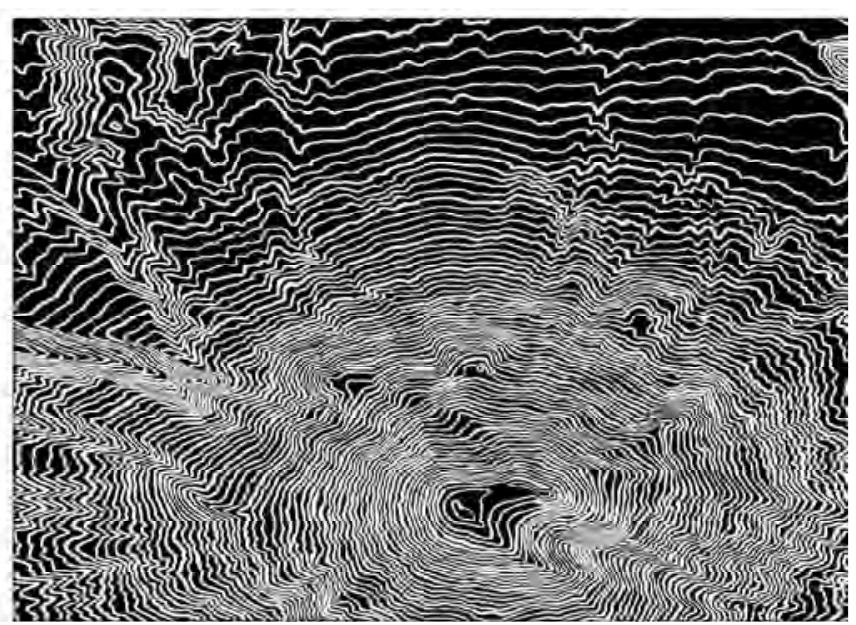

Figure 13. Final Raster Image

ii. Vector line Generation and addition of Elevation data

After finishing the cleaning process of the raster image ArcScan was used to generate vector lines along the middle of the raster pixels (See Figure 14). At this point the attribute table for the contour line was opened and elevations in $\mathrm{ft}$ were entered. Some maps had as few as 150 separate lines while others had almost 900.

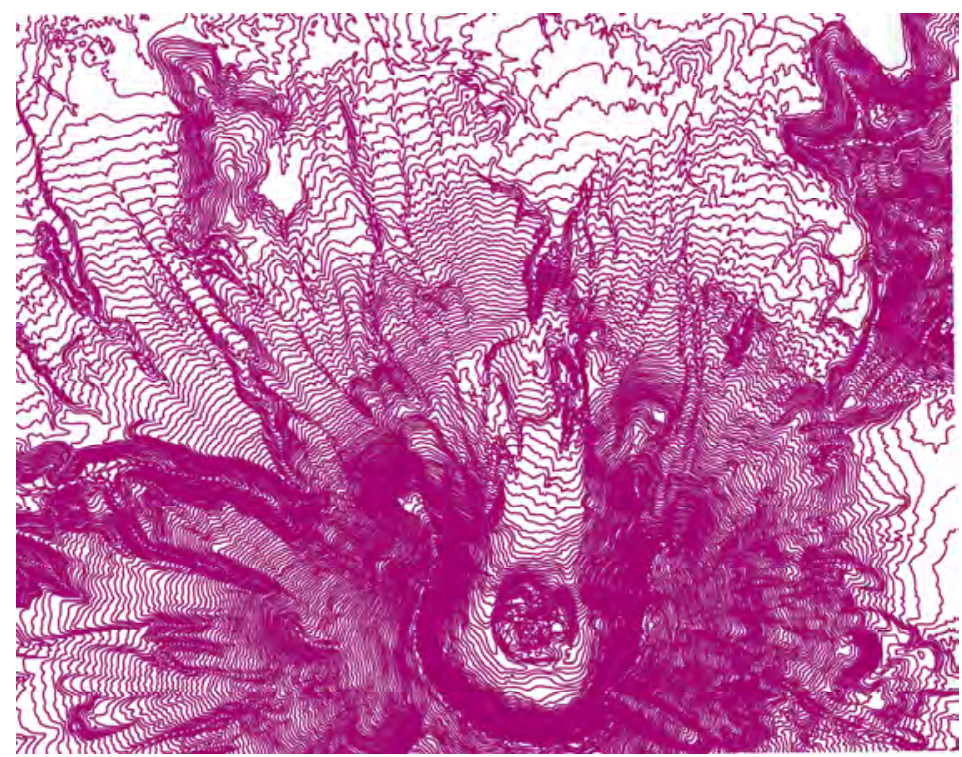

Figure 14. Vector lines 


\section{iii. Data Projection}

At this point our data's coordinate system was changed from its original geographic coordinates of GSC 1983 to a projected coordinate system of UTM, 1927, Zone 10. This allowed us to create a DEM in meters and the subsequent volume calculation in cubic meters $\left(\mathrm{m}^{3}\right)$.

Step 10-Point and DEM Generation

Finally, with all vector files generated and complete with elevations we were able to generate DEM's and calculate the volume of each map and the difference between the posteruption map and the pre-eruption maps. This was accomplished with ArcGIS Data Management option Feature to Points tool which created points from the final contour elevation lines (See Figure 15). After points were generated a DEM was produced with Inverse Distance Weighted (IDW) spatial interpolation tool, 3D Analyst (See Figure 16).
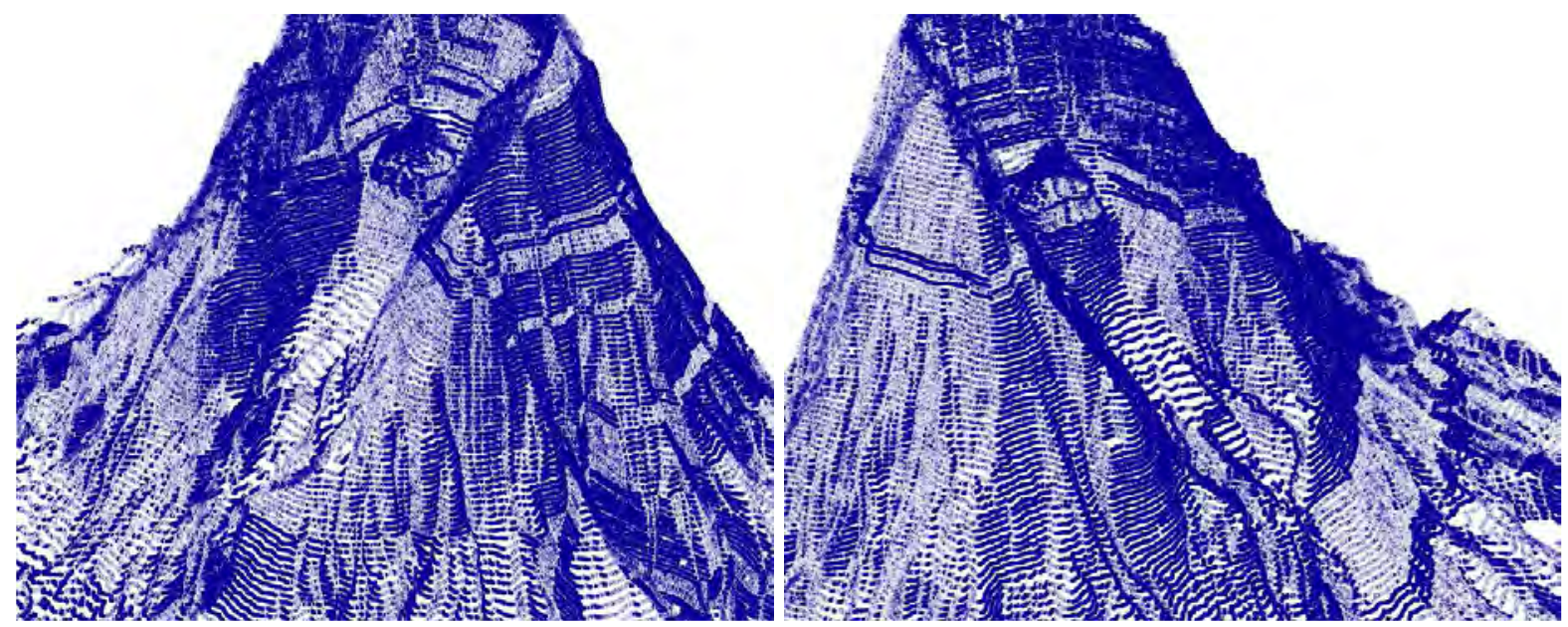

Figure 15. Point Image Rendered in ArcScene 


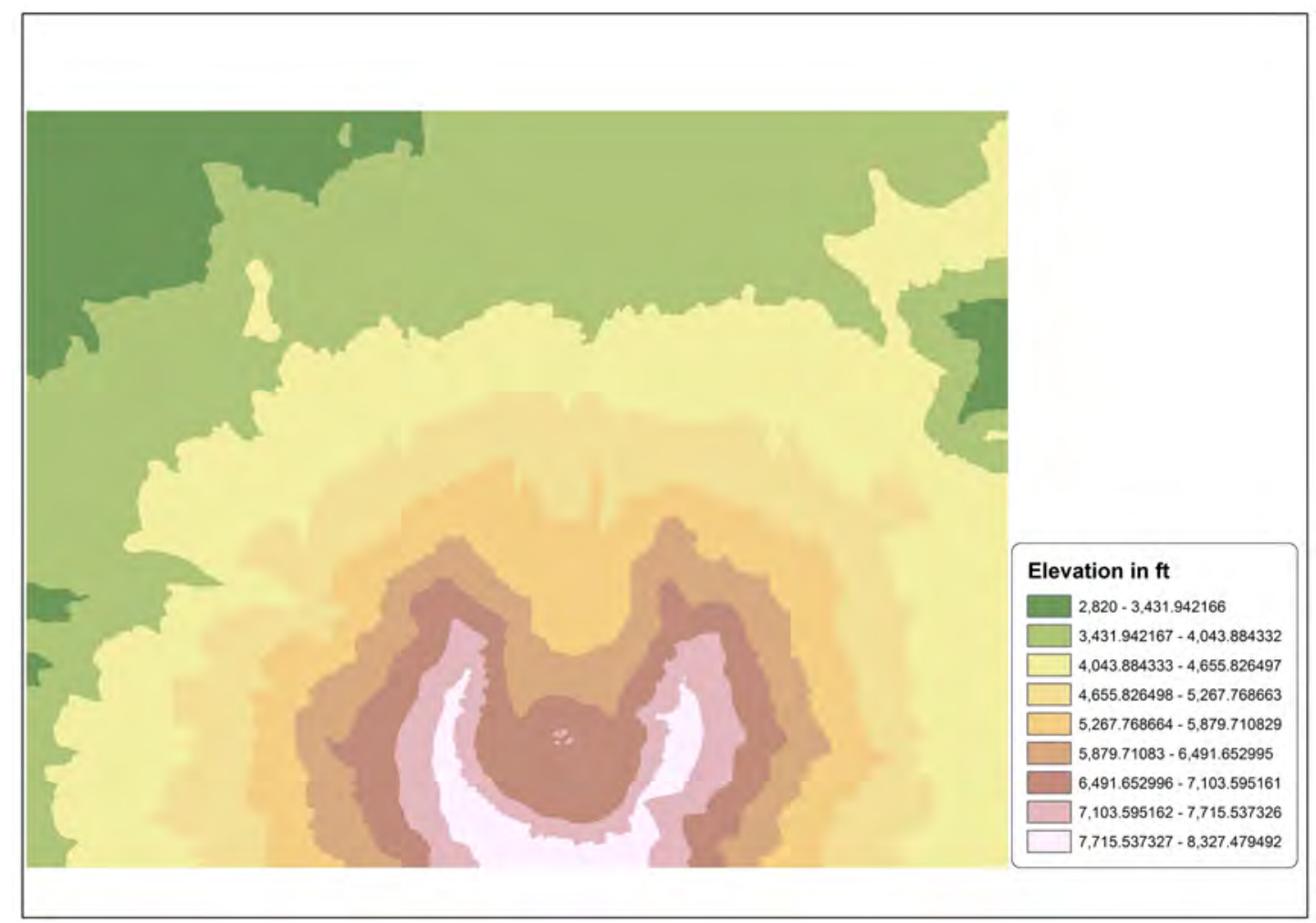

Figure 16. Digital Elevation Model Image

Step 11-Volume Calculation

After the IDW function created a DEM the 3D Analysis tool Cut and Fill created calculation layers of volume amounts. The program takes the surface of the elevation contours and calculates the underlying volume. Once this is accomplished for pre and post-eruption maps the two DEMs are entered into Raster Calculator and subtracted to obtain the volume difference image. This volume calculation was done for Mount St. Helens pre-eruption minus Mount St. Helens post-eruption, Cougar pre-eruption minus Goat Mountain post-eruption, Spirit Lake preeruption minus Spirit Lake West post-eruption, Elk Rock pre-eruption minus Hoffstadt Mountain and Elk Rock post-eruption. The reason we subtract Goat Mountain quad from Cougar being that Cougar 15 minute map contains the entire Goat Mountain 7.5 minute map. Likewise, Elk Rock 15 minute map contains both Hoffstadt Mountain and Elk Rock 7.5 minute maps. 


\section{Step 12. Difference assessment and Root Mean Square (RMS)}

In 2004 Mount St. Helens began a period or renewed activity. The USGS used satellite imagery and LIDAR sweeps of the mountain to create data and gather information. We utilized this LIDAR data to compare and contrast our contour elevation information. ${ }^{(20)}$ An accuracy assessment was not possible as the LIDAR data available was created in 2004 and our data was generated from photogrammetric aerial photos taken in 1980. To compare the two and call it accurate would be misleading.

In Table 1 we report the root mean square (RMS) of the difference between our data and the DEM created by the USGS in 2004. (20) RMS is a statistical measure of magnitude used in calculating averages when the data is both positive and negative, or sinusoidal. ${ }^{(21)}$ The root mean square statistical measure does not give us an accuracy assessment but RMS provides a rough yard stick to measure our results against. We calculated RMS by subtraction of the 2004 elevation values from the 1980 elevation values, squared the result, calculated the mean, and determined the square root of the resulting mean. See Table 1 for RMS value.

The differences between the LIDAR data and this study's data could be caused by a number of factors including: erosion of sediment and eruption materials, deposition of sediment and eruption materials, error artifacts from the DICE process, volcanic activity after 1980 and prior to 2004, especially volcanic re-growth in the eruption crater during the 2004 LIDAR collection, or other unforeseen factors. Re-growth of the dome recorded by the 2004 LIDAR data is most likely the main contributor to the large RMS error we calculated as Mount St. Helens added an additional 93,275,692.7 $\mathrm{m}^{3}$ of new volcanic material between 2004 and 2008. ${ }^{(22)}$ 
Table 1. RMS and Mean Difference

\begin{tabular}{|c|c|}
\hline Root Mean Square & Mean Difference \\
\hline $244.8429355 \mathrm{ft}$ & 51.28782 \\
\hline
\end{tabular}

The mean difference value (See Table 1) represents the change in elevation between our data and the 2004 LIDAR data. This value states that on average, each topographic map elevation is $51.28782 \mathrm{ft}$ lower than its LIDAR counterpart. The main objective of calculating the mean difference was to determine if a bias was present in the data. A negative value would have informed us the elevations were overestimated, a number close to 0 would have shown no bias either way, and our result shows a bias towards underestimating the elevation contours.

\section{Results}

The DICE processes, conversion of topographic maps into spatial elevation contour lines, were successful and the shapefile data was burned to compact disc and given to the USACOE. The original rectified images were also given to the Army Corps in .img format. The elevation contour lines generated accurately. We determined the accuracy of the lines by overlaying the generated vector lines on top of our original rectified images of the topographic maps. We also matched our contour lines with an outside data source, ESRI's river layer for Washington State, the maps proved to be accurately placed and spatially correct. With DEMs created from these contour lines we were able to calculate the total change in volume of Mount St. Helens (See Table 2). In the first row of Table 2 we see Mount St. Helens post eruption quad volume subtracted from its pre eruption counter part and the change in volume to its right. The change in volume means that during the 28 years between the creation of pre and post eruption maps the mountain experienced a 7.8 billion $\mathrm{m}^{3}$ increase in volume. The second row of Table 2 reveals a 4.3 billion $\mathrm{m}^{3}$ decrease in the volume of the area. This area was strongly impacted by the 
eruption and our calculations suggest that a large volume of material was removed. The third row shows Goat Mtn. quad subtracted from its pre eruption counterpart Cougar and 220.1 million $\mathrm{m}^{3}$ of material removed. Although this represents a large amount of erosion it is significantly smaller than the erosion in Spirit or Elk quads. These results are most likely due to the main path of the eruption bypassing the Goat Mtn. area and the south fork of the Toutle River. The fourth row shows Elk Rock post eruption subtracted from Elk Rock pre eruption and a 3.1 billion $\mathrm{m}^{3}$ loss of volume. The data for Elk Rock suggests heavy erosion in the main path of the eruption. The fifth shows Hoffstadt Mtn. subtracted from Elk Rock pre eruption with 734.1 million $\mathrm{m}^{3}$ of sediment and debris deposition. With only 734.1 million cubic meters of sediment deposited in the Hoffstadt Mtn. section of the river the data infers that the vast majority of eroded materials lies outside of our study area and further downstream.

Table 2. Pre and Post Eruption Volume Difference

\begin{tabular}{|c|c|c|}
\hline $\begin{array}{c}\text { Pre Eruption Map } \\
\mathbf{1 5} \text { minute series }\end{array}$ & $\begin{array}{c}\text { Post eruption Map } \\
\mathbf{7 . 5} \text { minute series }\end{array}$ & Change in Volume \\
\hline Mount St. Helens & Mount St. Helens & $7,870,546,345 \mathrm{~m}^{3}$ \\
\hline Spirit Lake & Spirit Lake West & $-4,335,917,517 \mathrm{~m}^{3}$ \\
\hline Cougar & Goat Mountain & $-220,149,557 \mathrm{~m}^{3}$ \\
\hline Elk Rock & Elk Rock & $-3,155,437,891 \mathrm{~m}^{3}$ \\
\hline Elk Rock & Hoffstadt Mountain & $734,102,545 \mathrm{~m}^{3}$ \\
\hline Total Sediment/Debris & & $8,604,648,890 \mathrm{~m}^{3}$ \\
\hline Volume & & $-7,711,504,965 \mathrm{~m}^{3}$ \\
\hline Total Erosion Volume & & \\
\hline
\end{tabular}

The total volume difference calculated between the pre and post eruptions maps is listed in the sixth row at 8.6 billion $\mathrm{m}^{3}$. This number is simply the total of all maps that had an 
increase in volume. The most likely cause for this increase in volume is the pyroclastic materials ejected by Mount St. Helens during the eruption. The two maps with an increase were Mount St. Helens and Hoffstadt Mtn. In row 7 of Table 2 we find the total decrease in volume of 7.7 billion $\mathrm{m}^{3}$. We attribute this decrease in volume to erosion due to erupted materials and the impact of the eruption explosion. This calculation is the total decrease in volume of Spirit Lake West, Goat Mtn., and Elk Rock. Besides the landslide, lahars, pyroclastic flows, and other eruption debris this volume calculation also includes any change in volume between 15 minute and 7.5 minute maps.

The overall picture our data paints is one of large scale deposition and erosion along the main eruption path. These calculations suggest that the vast majority of sediment was deposited below the north face of the mountain. The calculations show initial creation and deposition of sediment, large erosion as the eruption path travels west of Spirit Lake, decreasing erosion in the Elk Rock section of the north fork of the Toutle River, and finally renewed deposition in the Hoffstadt Mtn. reaches of the north fork of the Toutle.

\section{Discussion and Conclusion}

\section{A. Limits of the Data}

The volume calculated for total sediment and debris creation is 56 percent larger than prior estimations despite the fact that we used a DEM that did not smoothly interpolate between all points. The sediment erosion volume is far greater than previous studies have estimated and we attribute the difference to a number of factors. ${ }^{(14)}$ Our software discovered volume gain and loss in areas that could not have been eroded by the eruption (See Figure 17). The differences in volume for these areas were most likely caused by changes in topography between the time the two map sets were made, the differences in scale accuracy of the topographic map series, human 
error in creation of the original maps, possible editing mistakes made during the DICE process, and other unforeseen sources of error. It is also possible that original estimates of the eruption volume underestimated the sediment and debris created. The USACOE and the USGS were instructed to look concentrate their efforts on the North Fork of the Toutle river. Their estimates were need driven as repairs and cost estimates were needed as soon as possible. These factors combined with an immediate need for data to help protect the population downstream of the eruption could have contributed to the large differences between the USGS volume estimate and this project's estimate.

To calculate how much of the volume change is due to differences between map series, a baseline for error should be created. This could be accomplished by creating data for a similar mountain in the Cascade Range that had not experienced significant change. Mt. Hood would be ideal for this baseline data. Due to the time constraints of the project we were not able to create this data but future project that use the DICE method of creating data from historical topographic quads could include such data.

\section{B. Sediment Erosion and Deposition}

In Figure 17 we see the result of the cut and fill tool. Figure 17 displays volume areas overlaid on top of the post eruption map. The red indicates where volume increased, the blue where volume decreased, and the gray areas were volume stayed the same. The volume area change map demonstrates these volume estimates along the edge of the eruptions impact and beyond. South and east of the center of the map, Eruption Impact, and a segmented line delineating the eruption impact is shown. We can clearly see where volume has increased and decreased outside the eruption path and outside the extent of the eruption impact. 
Through use of the Cut and Fill tool I was able to see where volume increased and decreased throughout the study area. The volume increases calculated near Mount St. Helens and Hoffstadt Mtn. are easily explainable as deposition of eruption materials and sediment. The downstream erosion within Spirit Lake West, Elk Rock, and Goat Mtn. are not as easily explained by our calculations. According to our calculations almost all of the eroded materials, approximately 7 billion $\mathrm{m}^{3}$, were pushed outside our study area. Without expanding our volume calculations we are unable to confirm our calculations or determine if they are incorrect.

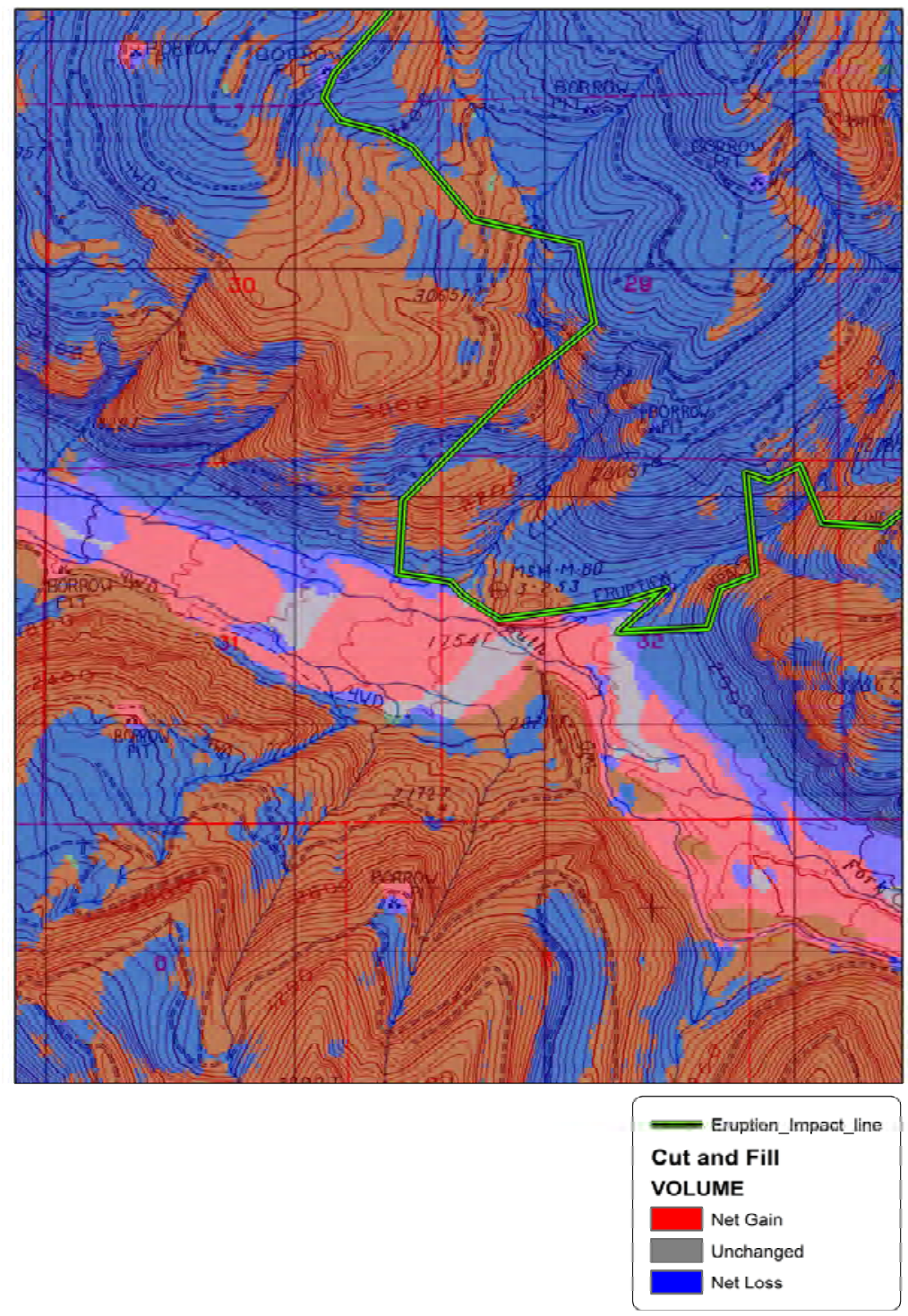

Figure 17. Goat Mtn. Volume Change Areas 


\section{Interpolation and DEMs}

The original goal of this project was to create DEMs that would enable the USACOE to more accurately predict where current and future sediment erosion would occur and this was accomplished. Creating an accurate DEM is a function of how close together the contour lines are placed and the interpolation algorithm. Without interpolating the area between contour lines the best DEM that could be accurately created for pre-eruption would be $14 \mathrm{~m}$ and the best surface for post-eruption would be a $7 \mathrm{~m} \mathrm{DEM}$. This is due to the wide interval between the elevation contours. The contours for pre-eruption and post-eruption are $80 \mathrm{ft}$ apart and $40 \mathrm{ft}$ respectively. Without proper interpolation the surface of the DEM will be terraced, like a set of stairs, and the resulting calculation will underestimate the total volume of sediment in some locations and overestimate in others.

We investigated interpolations methods that would create a smooth surface DEM and correct the terracing effect but could not apply them in time for this study. As explained to us by our USACOE partners, creation of DEMs from topographic maps is not a hard science but there are general guidelines. If you have $40 \mathrm{ft}$ contours you take half the contour distance, $20 \mathrm{ft}$ equals about $7 \mathrm{~m}$, and create a $7 \mathrm{~m}$ DEM. The software can create any size DEM. The smaller the DEM created past half the distance between contour lines, the less accurate the DEM. With more data inputs for the surface, such as stream locations, and an interpolation algorithm we feel confident the USACOE can produce a DEM smaller than the $7 \mathrm{~m}$ DEM we created in this project and as small as $3.5 \mathrm{~m}$ for post-eruption maps and $7 \mathrm{~m}$ for pre-eruption. The USACOE could create DEMs smaller than $3.5 \mathrm{~m}$ but their usefulness would be limited by their inaccuracy. These DEMs would have more error than could be accounted for and the DEM would not prove as useful in sediment erosion analysis and calculation. In order to create a DEM as small as $3 \mathrm{~m}$ 
the USACOE will incorporate surface data such as stream locations, erosion banks, and waterfalls. We did not attempt to collect this data because we did not have the time necessary or the funding for new LIDAR data of the study area.

Our earlier thought that the DICE process would reduce human error artifacts introduced into the contour data was inconclusive. When contour lines were farther apart, the DICE process was most accurate. It rendered a perfect copy of the contour elevation lines. When the elevation lines were closer together the DICE process had more issues. Due to the nature of the original drawing and printing process which created the topographic maps, sections of elevation data was often excluded. The original contours were hand drawn and a pen can only be made so small before there is no more room left to draw within. In cases where the original map creators left lines out or where numbers, grid lines, or symbols were drawn over sections of elevation contours the DICE process was unable to create line data. Each missing section of line was a judgment call as to whether it was drawn or the missing sections left out. Manual repair of contour lines was often required and this undoubtedly introduced human error into the exact position of the contour lines. Overall, this process was more accurate and less time consuming than heads up digitizing. By the end of our project we could create a map from the original non spatial image in less than three days. A professional using the older manual digitizing method needs 10-30 days to create the same data ${ }^{(11)}$.

\section{Recommendations for Further Study and Future of Project}

Were this project to continue we would recommend that the rest of the surrounding area be processed and contour lines extracted for all 7.5 minute quadrangle maps that fall within the four original 15 minute maps. This would require months of work but would provide a complete data set for the surrounding area and provide data of sediment that fell outside our clipped study 
area. Another source of data we feel should be investigated is a 1:10,000 scale map of the preeruption mountain that we were unable to use DICE upon. This map would have to be reprinted, or borrowed from the University of Oregon, and digitized in the traditional heads up environment. The Mount St. Helens 1:10,000 scale map could provide even finer detail on the exact volume of Mount St. Helens before it erupted. We would like to create this data for the USACOE if they would be willing to continue our partnership. We took extra efforts to procure this map from the University of Oregon but it proved unsuitable to our DICE method due completely to the style it had been originally printed with. This map was produced in a printing method called dithering and all but the major elevation lines were reduced to a barely recognizable trace by our processes. We experimented with image manipulation in Adobe Photoshop 6.0 but were unable to grow the lines once the dithered noise was removed. This presented the problem that with 50 percent of the elevation lines destroyed by the contour extraction process we would be adding more error into the elevation lines than would be reasonable. We finally determined this map could only be digitized using heads-up digitizing.

We would also continue our investigation into developing a model for generating a smooth surface interpolation that could correct the terracing effect between data points. A smooth interpolation DEM would have a larger volume than a terraced but we are unsure if this would generate more error in the data through overestimation.

The next step to take for this project is to submit the raw contour line data to the USACOE for interpolated DEM generation. Their DEM will incorporate stream location and other details that will increase the accuracy of the DEM. Sediment specialists will then use this data in a detailed analysis of sediment erosion, transport, and deposition. 


\section{References}

1. U S Geological Survey. Mount St. Helens Quadrangle Washington (Topographic). 1:62,500. 15 Minute Series. Washington D.C. 1958

2. U S Geological Survey. Cougar Quadrangle Washington (Topographic). 1:62,500. 15 Minute Series. Washington D.C. 1953

3. U S Geological Survey. Spirit Lake Quadrangle Washington (Topographic). 1:62,500. 15 Minute Series. Washington D.C. 1957

4. U S Geological Survey. Elk Rock Quadrangle Washington (Topographic). 1:62,500. 15 Minute Series. Washington D.C. 1953

5. U S Geological Survey. Mount St. Helens Quadrangle Washington (Topographic). 1:24,000. 7.5 Minute Series. Washington D.C. 1983

6. U S Geological Survey. Elk Rock Quadrangle Washington (Topographic). 1:24,000. 7.5 Minute Series. Washington D.C. 1983

7. U S Geological Survey. Spirit Lake West Quadrangle Washington (Topographic). 1:24,000. 7.5 Minute Series. Washington D.C. 1984

8. U S Geological Survey. Goat Mountain Quadrangle Washington (Topographic). 1:24,000. 7.5 Minute Series. Washington D.C. 1983

9. U S Geological Survey. Hoffstadt Mountain Quadrangle Washington (Topographic). 1:24,000. 7.5 Minute Series. Washington D.C. 1983

10. Yuyu H. and Lifan F., (1989). Setting up a Digital Elevation Model (DEM) on the basis of scanned raster data from contour line separations. International Yearbook of Cartography. 29, 99-107.

11. United States Geological Survey, (2008). Topographic Mapping Booklet. US Department of the Interior, National Mapping Division USGS. Accessed on May 20, 2009.

http://egsc.usgs.gov/isb/pubs/booklets/topo/topo.html

12. Brantley S.R., Meyers B., (1997). Mount St. Helens-From 1980 to 1996. United States Geological Survey Factsheet 070-97

13. Harris S.L., (1988). Fire Mountains of the West. Missoula: Mountain Press Publishing Company.

14. Tilling R.I., Topinka L., Swanson D.A., (1990). Eruptions of Mount St. Helens: Past, Present, and Future. US Geological Survey Special Interest Publication, Washington D.C. 
15. ESRI ArcGIS Geographical Information Systems information. Retrieved May 25, 2009 from Wikipedia: http://en.wikipedia.org/wiki/ArcMap

16. ERDAS Imagine. Retrieved May 25, 2009 from Wikipedia: http://en.wikipedia.org/wiki/ERDAS_IMAGINE

17. Definition and history of RADAR. Retrieved May 27, 2009. http://en.wikipedia.org/wiki/Radar

18. SPOT-1 operational background and DEM creating capability. Retrieved May 26, 2009. http://en.wikipedia.org/wiki/SPOT_(satellites)

19. RADARSAT-1 operational background and DEM creating capability. Retrieved May 26, 2009. http://en.wikipedia.org/wiki/RADARSAT

20. USGS 2004 LIDAR data and history. Retrieved June 2, 2009. http://vulcan.wr.usgs.gov/Volcanoes/MSH/Eruption04/LIDAR/framework.html

21. Root Mean Square definition. Retrieved June 2, 2009.

http://en.wikipedia.org/wiki/Root_mean_square

22. USGS, Mount St. Helens, Washington Eruption 2004 to Current. Retrieved June 3, 2009. http://vulcan.wr.usgs.gov/Volcanoes/MSH/Eruption04/framework.html

23. USGS, Map of Mount St. Helens and vicinity. Retrieved June 19, 2009. http://vulcan.wr.usgs.gov/Imgs/Gif/MSH/Maps/swwash_map.gif 